\title{
Perbedaan Pengaruh Metode Latihan Pliometrik Side Hop dan Barrier Hops Terhadap Kemampuan Tendangan Jauh Dalam Permainan Sepakbola Pada Atlet Putra Usia 11-13 Tahun SSB Zettle Meyer Karanganyar Tahun 2020
}

\section{The Difference In The Effect of Side Hop and Barrier Hops Plyometric Training Methods On The Ability Of Long Kick In Soccer Games In Male Athletes Aged 11-13 Years SSB Zettle Meyer Karanganyar 2020}

\author{
Thoha Isma Pratama ${ }^{a}$, Herywansyah ${ }^{b}$ \\ a Physical Education, Universitas Tunas Pembangungan Surakarta, Surakarta, Indonesia \\ ${ }^{b}$ Physical Education, Universitas Tunas Pembangungan Surakarta, Surakarta, Indonesia \\ email: thohaisma1234@gmail.com
}

\begin{tabular}{l}
\hline I N F O A R T I K E L \\
\hline Sejarah artikel: \\
Menerima 1 Januari 2021 \\
Revisi 21 Januari 2021 \\
Diterima 31 \\
Online 1 Februari 2021 \\
\hline Kata kunci: \\
Pliometrik Side Hop, Barrier \\
Hops, Sepakbola
\end{tabular}

Keywords:

Pliometrik Side Hop, Barrier Hops, Soccer

\begin{abstract}
ABSTRAK
Tujuan dari penelitian ini adalah : (1) untuk mengetahui perbedaan pengaruh latihan plyometrik side hop dan barrier hops terhadap kemampuan tendangan jauh pada atlet putra usia 11-13 tahun SSB Zettle Meyer Karanganyar Tahun 2020. (2) untuk mengetahui latihan mana yang berpengaruh lebih baik terhadap kemampuan tendangan jauh pada atlet putra usia 11-13 tahun SSB Zettle Meyer Karanganyar Tahun 2020. Metode penelitian yang digunakan adalah metode eksperimen dengan pretest-protest design. Populasi dalam penelitian ini adalah atlet putra usia 11-13 tahun SSB Zettle Meyer Karanganyar Tahun 2020 yang berjumlah 30 atlet, dengan teknik pengambilan sampling yang digunakan adalah Total Sampling. Sampel dibagi menjadi dua kelompok yaitu kelompok 1 sebanyak 15 atlet, mendapat perlakuan latihan plyometrik side hop dan kelompok 2 sebanyak 15 atlet, mendapat perlakuan latihan plyometrik barrier hops. Teknik pengumpulan data dilakukan dengan tes dan pengukuran menggunakan petunjuk tes kemampuan tendangan jauh (long pass). Teknik analisis data dilakukan dengan analisis statistik menggunakan uji t pada taraf signifikansi 5\%, untuk memenuhi asumsi hasil penelitian dilakukan uji persyaratan analisis yaitu dengan uji normalitas, uji, homogenitas, uji perbedaan dan persentase peningkatan. Berdasarkan hasil analisis data, maka penelitian ini menghasilkan simpulan sebagai berikut: (1) Ada perbedaan pengaruh yang signifikan antara latihan plyometrik side hop dan barrier hops, Hal ini dibuktikan dari hasil penghitungan tes akhir masing-masing kelompok yaitu thitung $=2,880$ lebih besar dari pada tabel $=2,145$ dengan taraf signifikansi $5 \%$. (2) latihan plyometrik side hop lebih baik pengaruhnya dari pada barrier hops, dilihat berdasarkan dari hasil persentase kemampuan tendangan jauh yang menunjukkan bahwa kelompok 1 sebesar 22,19\% > kelompok 2 sebesar $7,22 \%$.

Kata kunci : Pliometrik Side Hop, Barrier Hops, Sepakbola
\end{abstract}


Thoha Isma Pratama, Herywansyah

Style APA dalam
mensitasi artikel ini:
Thoha Isma Pratama,
(2020). Merbedaan
Pengaruh Metode Latihan
Pliometrik Side Hop dan
Barrier Hops Terhadap
Kemampuan Tendangan
Jauh Dalam Permainan
Sepakbola Pada Atlet
Putra Usia 11-13 Tahun
SSB Zettle Meyer
Karanganyar Tahun 2020.
Jurnal Ilmiah Penjas7 (1) 1-
12.

12.
The objectives of this study were: (1) to determine the difference in the effect of side hop and barrier hops plyometric training on the long kick ability of male athletes aged 11-13 years old SSB Zettle Meyer Karanganyar in 2020. (2) to determine which exercises had a better effect. against the long kick ability of male athletes aged 11-13 years SSB Zettle Meyer Karanganyar in 2020.

The research method used was an experimental method with a pretest-protest design. The population in this study were male athletes aged 11-13 years SSB Zettle Meyer Karanganyar in 2020, totaling 30 athletes, with the sampling technique used was Total Sampling. The sample was divided into two groups, namely group 1 as many as 15 athletes, received side hop plyometric training treatment and group 2 as many as 15 athletes, received barrier hops plyometric training treatment. The data collection technique was carried out by tests and measurements using the long pass test instructions. The data analysis technique was carried out by statistical analysis using the t test at a significance level of $5 \%$. To meet the assumptions of the research results, the analysis requirements test was carried out, namely the normality test, homogeneity test, difference test and percentage increase.

Based on the results of data analysis, this study produces the following conclusions: (1) There is a significant difference in the effect between side hop and barrier hops plyometric exercises. This is evidenced by the results of the calculation of the final test for each group, namely tcount $=2.880$ is greater than the t table $=2.145$ with a significance level of 5\%. (2) side hop plyometric exercise has a better effect than barrier hops, as seen from the results of the percentage of long kick ability which shows that group 1 is $22.19 \%>$ group 2 is $7.22 \%$.

Keywords: Pliometrik Side Hop, Barrier Hops, Soccer

\section{Pendahuluan}

Hakekat olahraga merupakan kegiatan fisik yang mengandung sifat permainan dan berisi perjuangan melawan diri sendiri atau melawan orang lain atau konfrontasi dengan unsur-unsur alam. Diantara berbagai banyak cabang olahraga salah satunya adalah sepakbola,sepakbola merupakan salah satu cabang olahraga yang paling banyak digemari oleh sebagian besar manusia yang ada di dunia ini termasuk di Indonesia. Sepakbola digemari oleh semua lapisan masyarakat baik laki-laki atau perempuan dari tingkat daerah, nasional, dan internasional, dari usia anak-anak dewasa hingga orang tua, mereka senang memainkan sendiri atau sebagai penonton. Untuk saat ini permainan sepakbola tidak sekedar dilakukan untuk tujuan rekreasi dan pengisi waktu luang akan tetapi dituntut suatu prestasi yang optimal. Prestasi yang tinggi hanya dapat 
Perbedaan Pengaruh Metode Latihan Pliometrik Side Hop dan Barrier Hops Terhadap Kemampuan Tendangan Jauh Dalam Permainan Sepakbola Pada Atlet Putra Usia 11-13 Tahun SSB Zettle Meyer Karanganyar Tahun 2020

Thoha Isma Pratama, Herywansyah

dicapai dengan latihan-latihan yang direncanakan dengan sistematis dan dilakukan secara terus menerus disertai pengawasan dan bimbingan pelatih yang profesional. Menurut Cipta Nugraha Andi (2012: 23), sepakbola adalah suatu permainan yang dilakukan dengan jalan menyepak bola kian kemari untuk diperebutkan di antara pemain-pemain yang mempunyai tujuan untuk memasukkan bola ke gawang lawan dan mempertahankan gawang sendiri agar tidak kemasukan bola. Menurut Agus Salim (2008: 10) dijelaskan pada dasarnya sepakbola adalah olahraga yang memainkan bola dengan mengunakan kaki. Tujuan utamanya dari permainan ini adalah untuk mencetak gol atau skor sebanyak-banyaknyan yang tentunya harus dilakukan sesuai dengan ketentuan yang ditetapkan. Untuk bisa membuat gol harus tangkas, sigap, cepat, dan baik dalam mengontrol bola. Sehingga untuk dapat melakukan semuanya itu dengan cara menendang, karena menendang adalah teknik dasar yang paling dominan agar bola secepat mungkin berada di depan gawang lawan. Menendang dalam permainan sepakbola adalah suatu usaha untuk memindahkan bola dari satu titik ke titik lain dengan menggunakan kaki. Untuk menghasilkan tendangan yang jauh selain dibutuhkan penguasaan teknik yang baik, kemampuan fisik juga ikut berperan karena hasil tendangan yang baik selain didapatkan dari penguasaan teknik yang baik juga kondisi fisik yang baik pula. Dalam permaianan sepakbola untuk menghasilakan tendangan yang jauh, dibutuhkan power otot tungkai oleh karena itu perlu melatih power otot tungkai. Dalam melatih power otot tungkai, dapat digunakan salah satu metode latihan yaitu dengan metode Plyometrik. Adapun materi latihan Plyometrik untuk meningkatkan daya ledak otot tungkai adalah latihan Side Hop (loncat menyamping)dan Barrier Hops (Loncat ke depan dengan rintangan). Kemampuan menendang bola agar menghasilkan tendangan yang tepat sasaran atau yang sesuai dengan yang kita inginkan baik itu tendangan ke gawang (shooting at the goal) atau mengumpan (passing) maka gerakan eksplosif otot tungkai sangat dibutuhkan untuk memperoleh gaya yang besar. Dari keseluruhan uraian diatas, penulis ingin 
Thoha Isma Pratama, Herywansyah

meningkatkan keterampilan hasil tendangan jauh pada atlet putra usia 11-13 tahun di SSB “ZETTLE MEYER” Karanganyar. Kemampuan tendangan bola dipengaruhi oleh power otot tungkai, dan untuk meningkatkan power otot tungkai dapat melakukan latian plyometrik antara lain side hop dan barrier hops.

Setiap pemain sepak bola diharapkan memiliki kondisi fisik yang baik dalam menunjang keberhasilan bermain sepak bola. Untuk memiliki kondisi fisik yang baik, maka di perlukan latihan fisik yang teratur. Menurut Harsono, dkk. (2005, hlm. 41) mengungkapkan "latihan fisik adalah latihan yang bertujuan untuk meningkatkan kondisi fisik, yaitu faktor yang amat penting bagi setiap atlet". Adapun kondisi fisik yang harus dimiliki oleh pemain sepak bola yang diungkapkan oleh Hasanah (2009, hlm. 45) mengungkapkan bahwa “apa saja yang kita butuhkan untuk bisa bermain sepakbola dengan baik? Pertama-tama adalah keunggulan fisik yang meliputi: ketahanan (endurance), kekuatan (strength), dan kecepatan (speed)". Giriwijoyo (1992:78) menjelaskan Latihan ialah upaya sadar yang dilakukan secara berkelanjutan dan sistematis untuk meningkatkan kemampuan fungsional raga yang sesuai dengan tuntutan penampilan cabang olahraga itu, untuk dapat menampilkan mutu tinggi cabang olahraga itu baik pada aspek kemampuan dasar (latihan fisik) maupun pada aspek kemampuan keterampilannya (latihan teknik). Prinsip-prisip latihan adalah (1) Prinsip pemanasan tubuh (warming-up principle), (2) Prinsip beban lebih (overload principle), (3) Prinsip sistematis (systematic principle), (4) Prinsip intensitas (intensity principle), (5) Prinsip pulih asal (recovery principle), (6) Prinsip variasi latihan, (7) Prinsip perkembangan multilateral, (8) Prinsip individualisasi, (9) Prinsip spesifik (specificity principle). Harsono (2004). Para atlit dan pelatih telah berupaya mencari berbagai metode untuk meningkatkan kecepatan dan kekuatan. Kecepatan dipadu dengan kekuatan menghasilakan power, dan power mutlak diperlukan untuk melakukan sebagian besar keterampilan olahraga, baik itu berupa clean and jerk pada angkat besi atau pun melakukan tendangan jauh pada permainan sepakbola dalam penelitian ini dan juga berbagai olahraga lainya. Asal istilah plyometrik diperkirakan 
Perbedaan Pengaruh Metode Latihan Pliometrik Side Hop dan Barrier Hops Terhadap Kemampuan Tendangan Jauh Dalam Permainan Sepakbola Pada Atlet Putra Usia 11-13 Tahun SSB Zettle Meyer Karanganyar Tahun 2020

Thoha Isma Pratama, Herywansyah

dari kata bahasa yunanai "pleythuein" berarti "memperbesar" atau "meningkatkan", atau dari akar kata bahasa yunani "plio" dan "metric", masing-masing bearti "lebih banyak" dan "ukuran" (Chu,1983; Gambeta, 1981; Wilt \& Ecker, 1970). Menurut buku yang ditulis oleh James C. Radcliffe \& Robert C. Farentinos dan diterjamahkan oleh M. Furqon H. \& Muchsin Doewes Plyometrik ialah :

Suatu metode untuk meningkatkan daya ledak (explosive power), suatu komponen penting dari sebagian besar prestasi atau kinerja oalahraga. Dari sudut pandang praktis latian plyometrik relatif mudah diajarkian dan dipelajari, serta menempatkanya lebih sedikit tuntutan fisik tubuh dari pada latihann kekuatan atau daya tahan. Plyometrik dengan cepat menjadi bagai intergral dari program latian keseluruhan dalam berbagai cabang olahraga (2002 : 1). Gerakan pliometrik ditujukan kepada tiga kelompok otot besar dalam tubuh, yakni kelompok otot tungkai dan pinggul, kelompok otot bagian tengah tubuh yaitu otot perut, punggung dan kelompok otot dada, bahu, dan lengan. Tetapi, tekanan pelatihannyaterutama ditujukan terhadap kelompok otot tungkai dan pinggul (M. Furqon dan Muchsin Doewes, 2002:22) dengan cara : 1)Bounding, yaitu loncatan dengan kedua tapak kaki bertumpu pada lantai, melembung maksimum ke atas agar tercapai loncatan horizontal sejauh-jauhnya, 2) Leapping, yaitu meloncat vertikal dan horizontal semaksimum mungkin, dengan dua loncat atau satu lompat tungkai, 3) Hoppping, yaitu loncatan dua tapak kaki vertikal maksimum dengan didahului menekukan tungkai pada lutut, dimana yang dipentingkan adalah luasnya gerakan sendi lutut. 4) Jumping, yaitu meloncat setinggi mungkin tanpa meghiraukan berapa jauhnya loncatan horizontal kedepan. 5) Skepping, yaitu melompat dan melangkah bergantiandengan tujuan baik tinggi lompatan maupun jauhnya jarak lompatan horizontal, 6) Ricochet, yaitu meloncat dengan cepat, dimana tinggi dan jauhnya loncatan seminimal mungkin. Latihan pliometrik bertujuan untuk meningkatkan daya ledak otot. Latihan daya ledak otot tungkai pada dasarnya dapat dilakukan dengan 
berbagai materi latihan dengan latihan pliometrik. Salah satu cara latihan pliometrik tersebut adalah side jump dan barrier hops.

Side hop dalam pelaksanaannya mempunyai aturan sendiri, menurut J.C. Radclife dan R.C. Farentinous yang diterjemahkan oleh M. Furqon dan Muchsin Doewes (2002:38), latian ini mengunakan 2 buah dengan tinggi kira-kira 18-26 inci. Secara khusus gerakan ini mengembangkan otot-otot abductor paha, stbilizer lutut dan ankle serta meningkatkan power samping yang eksplosif diseluruh paha dan pinggul. Latihan ini sangat berguna untuk semua aktifitas yang mengunakan gerakan ke samping.

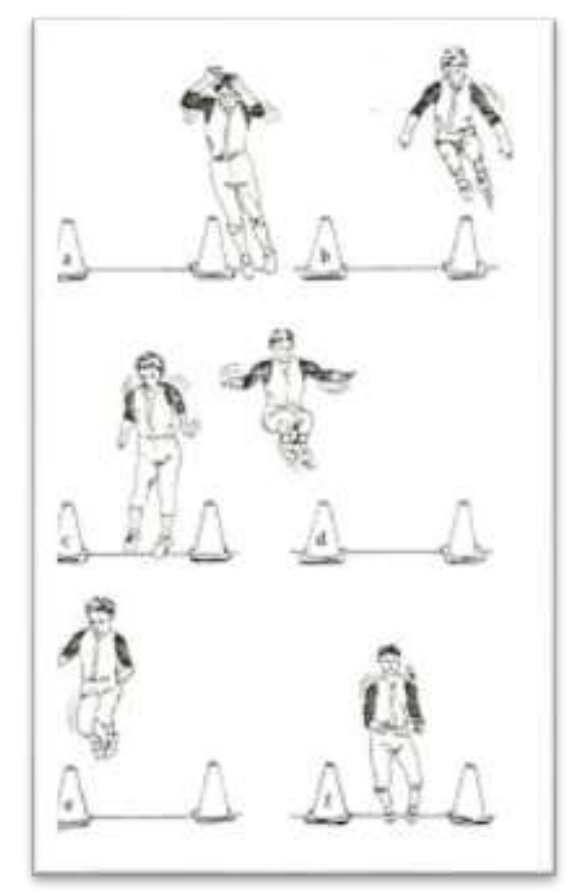

Gambar 10. Latihan side hop

Sumber : James C. Radcliffe dan R.C Farentinus (2002: 38)

Side hop merupakan latihan untuk meningkatkan power otot tungkai dan pinggul. Latihan ini merupakan bagian dari latihan hopping pada metode pliometrik yang mana mencapai ketinggian maksimum gerakan kaki, yakni mencapai jarak horisontal dengan tubuh merupakan faktor penting kedua. Latihan Side Hop merupakan bagian metode latihan pliometrik, metode ini melatih power otot tungkai 
Thoha Isma Pratama, Herywansyah

yang mana power merupakan gabungan dari dua unsur yaitu kecepatan dan kekuatan, selain dua unsur tersebut dibutuhkan pula pengetahuan tentang tehnik menendang bola dengan benar.

Latihan daya otot (eksplosif power) tungkai yang kedua adalah dengan Barrier Hops (loncat rintangan). Menurut Donal A. Chu(1992:40) Latihan Barrier Hops adalah: "latihan yang dilakukan pada gawang-gawang atau rintangan-rintangan yang tingginya (antara $30-90 \mathrm{~cm}$ ) diletakkan disuatu garis dengan jarak yang ditentukan dengan kemampuan. Rintangan akan jatuh bila atlet membuat kesalahan, start dimulai dengan berdiri di belakang rintangan, gerakan meloncat yang melewati rintangan-rintangan dengan kedua kaki bersaman. Gerakan dimulai dari pinggang dan lutut merenggang. Gunakan ayunan kedua lengan untuk menjaga keseimbangan dan mencapai ketinggian. Lebih jelasnya lihat gambar 4

\section{Barrier Hops (Hurdle Hops)}
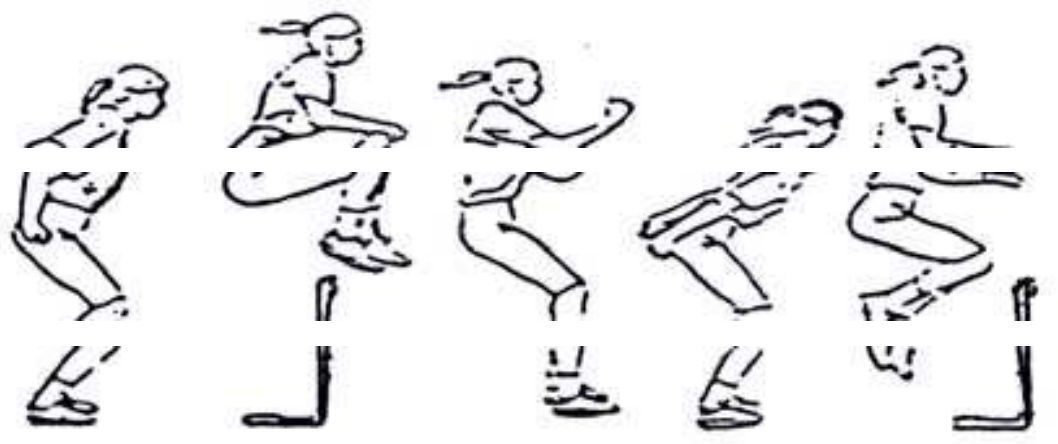

Gambar 11. Latihan Barrier Hops

Sumber : Donal A Chu (1940: 40)

Barrier Hops merupakan salah satu dari metode latihan pliometrik yang mana latihan Barrier Hops bagian dari latihan Hopping. Hopping merupakan metode latihan pliometrik yang khusus meningkatkan power otot tungkai. Anatomi fungsional hopping meliputi(1) flexi paha, melibatkan otot Sartorius, Iliacus dan Gracillis, (2) Ekstensilutut, melibatkan otot-otot tensor fascialatae, vastus lateralis, medialis, intermedius, dan rectus 
Thoha Isma Pratama, Herywansyah

femoris, semitendinosus dan semi membranousserta juga melibatkan otot-otot gastrocnemius, peroneus dan soleus, dan (3) Aduksi dan Abduksi Paha, melibatkan otototot gluteus medius danminimus dan Adductorlongus, Brevis, magnus, minimus dan Hallucis.Latihan Barrier Hops melatih power yang mana powermerupakan gabungan dari dua unsur yaitu kecepatan dan kekuatan. Untuk menendangbola dibutuhkan sudut tendangan dan kecepatan gerak bola, oleh karenalatihan Barrier Hops melatih kekuatan dan kecepatan gerakan tungkaiuntuk memberi daya dorong pada bola supaya lebih cepat maka disinyalirlatihan ini mempunyai kontribusi terhadap jauhnya tendangan.

Kemampuan teknik menguasai bola merupakan syarat utama bagi setiap pemain sepakbola dimana sangat erat hubunganya dengan prestasi seseoarang sebagai anggota tim. Oleh karena itu setiap pemaian perlu mempelajari unsur-unsur teknik secara seksama salah satunya teknik menendang bola. (Arma Abdoellah, 1981 : 420). Sucipto dkk. (2000:11) menyatakan, “Menendang bola merupakan pola gerak dominan yang paling penting dalam permainan sepak bola. Pada dasarnya bermain sepak bola itu tidak lain dari permainan menendang bola." Berdasarkan beberapa penjelasan tersebut di atas maka dapat disimpulkan bahwa penguasaan keterampilan teknik dasar menendang bola bagi seorang pemain sepak bola adalah penting, karena sangat berkaitan dengan tujuan permainan sepak bola yaitu memasukkan bola ke gawang lawan. Tanpa penguasaan teknik menendang bola yang memadai maka tujuan permainan sepak bola cenderung tidak akan tercapai secara maksimal.

\section{Metode}

Desain penelitian ini menggunakan "Pretest-Posttest Design". Pembagian kelompok eksperimen didasarkan pada tes kemampuan Tendangan Jauh pada tes awal. Setelah hasil tes awal dirangking, kemudian subjek yang memiliki kemampuan setara dipasang-pasangkan ke dalam kelompok 1 (K1) dan kelompok 2 (K2). Dengan demikian kedua kelompok tersebut sebelum diberi perlakuan merupakan kelompok yang sama. Apabila pada akhirnya terdapat perbedaan, maka hal ini disebabkan oleh 
Perbedaan Pengaruh Metode Latihan Pliometrik Side Hop dan Barrier Hops Terhadap Kemampuan Tendangan Jauh Dalam Permainan Sepakbola Pada Atlet Putra Usia 11-13 Tahun SSB Zettle Meyer Karanganyar Tahun 2020

Thoha Isma Pratama, Herywansyah

pengaruh perlakuan yang diberikan. Pembagian kelompok dalam penelitian ini dengan cara ordinal pairing. Sampel yang digunakan dalam penelitian ini sebanyak 30 atlet. Teknik pengumpulan data menggunakan petunjuk tes kemampuan tendangan jauh (long pass) dari Djide yang dikutip dalam Arifin (2009: 38).

\section{Hasil dan Pembahasan}

Berdasarkan hasil pengujian hipotesis dengan uji perbedaan nilai $\mathrm{t}$ antara tes awal dan tes akhir pada kelompok 1 (kelompok yang mendapat perlakuan latihan plyometrik side hop $)=3,214$, sedangkan $t_{\text {tabel }}=2,145$. Ternyata $t$ yang diperoleh $>t_{\text {tabel, }}$ yang berarti hipotesis nol ditolak. Hal ini menunjukkan adanya perbedaan yang signifikan antara hasil tes awal dan tes akhir pada kelompok 1 . Kelompok 1 memiliki kemampuan melakukan tendangan jauh (long pass) yang disebabkan oleh metode yang diberikan, yaitu metode latihan plyometrik side hop. Pada analisa data yang didapat antara tes awal dan tes akhir pada kelompok 2 (kelompok yang mendapat latihan plyometrik barrier hops) $=2,602$, sedangakan $t_{\text {tabel }}=2,145$. Ternyata $\mathrm{t}$ yang diperoleh $>t_{\text {tabel, }}$ yang berarti hipotesis nol ditolak. Dengan demikian dapat disimpulkan bahwa terdapat perbedaan yang signifikan antara hasil tes awal dan tes akhir pada kelompok 2. Berarti kelompok 2 memiliki kemampuan melakukan tendangan jauh (long pass) yang disebabkan oleh metode yang diberikan, yaitu metode latihan plyometrik barrier hops.

Pada analisa data yang lain yaitu pada hasil uji perbedaan yang dilakukan terhadap tes akhir pada kelompok 1 dan kelompok 2, diperoleh nilai t sebesar 2,880, sedangkan $t_{\text {tabel }}=2,145$, ternyata $t$ yang diperoleh $>t_{\text {tabel }}$, yang berarti hipotesis nol ditolak. Hal ini menunjukkan bahwa setelah diberikan perlakuan selama 6 minggu, terdapat perbedaan yang signifikan antara hasil tes awal dan tes akhir pada kelompok 1 dan kelompok 2. Kelompok 1 dan kelompok 2 diberikan perlakuan (threatment) dengan metode latihan yang berbeda terhadap kemampuan tendangan jauh (long pass) dalam sepakbola. 
Adanya perbedaan yang signifikan antara kelompok 1 dan kelompok 2 maka dilakukan penghitungan nilai perbedaan kemampuan tendangan jauh (long pass) dalam sepakbola dalam persen pada kelompok 1 dan kelompok 2. Kelompok 1 memiliki nilai persentase kemampuan melakukan tendangan jauh (long pass) sebesar 22,19\%, sedangkan kelompok 2 memiliki nilai persentase kemampuan melakukan tendangan jauh (long pass) sebesar 7,22\%. Hal ini menunjukkan kelompok 1 memiliki kemampuan melakukan tendangan jauh (long pass) dalam sepakbola yang lebih baik dari pada kelompok 2, karena metode latihan plyometrik side hop sangat efektif untuk meningkatkan kemampuan tendangan jauh (long pass) dalam sepakbola. Dalam metode ini atlet melakukan rangkaian gerakan loncat yang eksplosive secara cepat tidak maju kedepan melainkan geser ke kanan dan ke kiri. Latihan ini menggunakan alat meskipun memakai alat tidak harus kita mengunakan kerucut latian tetepi mengunakan atau memodifikasi alat lain asalkan ukurannya sesuai contohnya dengan kun yang atasnya dikasih bola atau rintangan lainnya. Dengan melakukan latihan side hop sesering mungkin maka tidak menutup kemungkinan akan menambah kekuatau otot paha sehingga dapat menyebabkan kemampuan tendangan jauh (long pass) yang baik, serta mendukung peningkatan kemampuan tendangan jauh (long pass) yang lebih optimal.

Dari hasil analisis uji perbedaan, dapat diuraikan hal-hal pokok sebagai hasil dari penelitian ini yaitu:

1. Latihan plyometrik side hop dan barrier hops berpengaruh terhadap kemampuan tendangan jauh dalam permainan sepakbola.

2. Latihan plyometrik side hop lebih baik pengaruhnya dari pada latihan plyometrik barrier hops terhadap kemampuan tendangan jauh dalam permainan sepakbola.

\section{Simpulan}

Berdasarkan hasil penelitian dan hasil analisis data yang telah dilakukan, dapat diperoleh kesimpulan sebagai berikut: 
1. Ada perbedaan pengaruh yang signifikan antara latihan plyometrik side hop dan latihan plyometrik barrier hops terhadap kemampuan tendangan jauh pada atlet putra usia 11-13 tahun SSB Zettle Meyer Karanganyar Tahun 2020. Hal ini dibuktikan dari hasil penghitungan tes akhir masing-masing kelompok yaitu thitung $=2,880$ lebih besar dari pada tabel $=2.145$ dengan taraf signifikasi 5\%.

2. Latihan plyometrik side hop lebih baik pengaruhnya dari pada latihan plyometrik barrier hops terhadap kemampuan tendangan jauh pada atlet putra usia 11-13 tahun SSB Zettle Meyer Karanganyar Tahun 2020. Berdasarkan persentase hasil kemampuan tendangan jauh menunjukkan bahwa kelompok 1, kelompok yang mendapat perlakuan dengan latihan plyometrik side hop adalah 22,19\% > kelompok 2, kelompok yang mendapat perlakuan latihan plyometrik barrier hops adalah $7,22 \%$.

\section{Referensi}

Andi Cipta Nugraha. 2012. Mahir Sepakbola. Bandung. N uansa Cendekia.

Arifin Zainal. 2008. Metodelogi Penelitian Pendidikan. Surabaya : Lentera Cendikia.

Beltasar Tarigan. 2001. Pendekatan Keterampilan Taktis dalam Pembelajaran Sepakbola. Jakarta: Depdiknas. Direktorat Jenderal Pendidikan Dasar dan Menengah. Bekerjasama Dengan Direktorat Jenderal Olahraga.

Chu, Donald. 2004. Jumping Into Plyometrics. Diterjemahkan Oleh M. Furqon H \& Muchsin Doewes Urqoh H. Surakarta : Program Pascasarjana Universitas Sebelas Maret.

Danny, Mielke. 2008. Dasar-Dasar Sepakbola. Alih Bahasa Eko Wahyu Setiawan. Bandung : Pakar Raya.

Erich, F., Dieter. K. dan Gunter, J. Sepakbola: Pembinaan Teknik dan Kondisi. Jakarta: PT Gramedia. 1978

Griwijoyo, Y.S. Sentoso. 1992.Ilmu Faal Olahraga. Bandung : FPOK IKIP Bandung. Harsono. 2005. Coaching dan Aspek-Aspek Psikolgis Dalam Coaching. Jakarta. CV. Tambak Kusuma. 
2011. Latihan Kondisi Fisik. Bandung. Senarai Pustaka.

Hasanah Ina. 2009. Sepak Bola. Bandung: PT. Indah Jaya Adi Pratama.

I Komang Bagiasa. 2011. "Pengaruh Pelatihan Plaiometrik Terhadap Hasil Lompat Jauh Ditinjau dari Daya Ledak Otot Tungkai pada SMP Negeri 3 Sawan tahun pelajaran 2010/2011". Skripsi. Hal 48.

Kusuma Mia. 2015. Penelitian Pendidikan Perjasoerkes. Bandung : Alfabneta.

Mikdar, U.Z. 2006. Hidup Sehat : Nilai Inti Berolahraga. Jakarta : Depdiknas, Dirjen Dikti, Direktorat Ketenagaan.

Mulyadi dan Johny Setiawan. 2005. Sistem Perencanaan Dan Pengendalian Manajemen, Sistem Pelipat Ganda, Kinerja Perusahaan. Jakarta : Rineka Cipta.

M. Furqon H \& Muchsin Doewes Urqoh H. Plyometrik Untuk Meningkatkan Power. Surakarta : Program Pascasarjana Universitas Sebelas Maret.

Nurhasan. 2009. Tes dan Pengukuran Olahraga. FPOK UPI.

Radclife, J.C \& Farentinous, R.ZC. 2002. Pliometrik Untuk Meningkatkan Power. Terjemahan Oleh M. Furqon H \& Muchsin Doewes Urqoh H. Surakarta : Program Pascasarjana Universitas Sebelas Maret.

Sucipto, dkk. 2000. Sepakbola. Jakarta: Departemen Pendidikan Nasional Direktorat Jendral PEndidikan Dasar dan Menengah Bagian Proyek Penataan Guru SLTP Setara DIII.

Sugiyono. 2013. Metode Penelitian (Kuantitatif, Kualitatif, dan RED). Bandung : Alfabeta.

Suharsimi Arikunto. 2009. Manajemen Penelitian. Jakarta : Rineka Cipta.

Sukma Aji. 2016. Buku Olahraga Paling Lengkap. Jakarta : Ilmu.

Sutrisno Hadi. 2000. Metodologi Research Jilid 4. Yogyakarta: Andi Offset.

Zaenal Arifin. 2009. Evaluasi Pembelajaran. Bandung : PT. Rosda Karya.

Zidane Muhdhor Al-Hadiqie. 2013. Menjadi Pemain Sepakbola Profesional Teknik, Strategi, Taktik Menyerang dan Bertahan. Jakarta: Kata Pena. 